1) Texto traduzido parao

português por Andréa Monteiro

Uglar, com revisão técnica da

Professora Live Docente Anna

Maria Balogh. Opresente texto é

publicado pela Novos Olhares com

autorização do autor, obtida em

1998, quando de sua visita a São

Paulo, e é reprodução da versão

originalmente feita pela revista

Novos Olhares, $n^{\circ}$ 03, 1999.

2) Este texto foi primeiramente

apresentado sob a forma de uma

conferência introdutória a colóquio

IComunicação e sociedadel que

realizou-se em Lyon, nos dias 12 e

13 de dezembro de 1991. Nesta

versão, ele foi publicado pelo

Programa Rhône-Alpes Recherche

em ciências humanas nos anais do

colóquio | Communication et

nouvelles technologies, textos

reunidos por Claire Belisie, 1993).

Profundamente modificadoe

largamente completado, ele serviu

de base para a redação de uma

contribuição ao número especial da

revista Hermès, Communication et

politique, intitulado 'L'espace public,

au-delà de la sphère politique" $\left(n^{\circ}\right.$

17, sob a direção de Gilles Gauthier,

André Gosselin e Jean Mouchon,

publicação prevista para 1995).

3) Louis Quéré, Des miroirs

équivoques: aux origines de la

communication moderne, Aubier

Montaigne, Paris, 1982, 215 páginas.

4)Jürgen Habermas, L'Espace

public, tradução francesa, Payot,

Paris, 1978, nova edição 1993.

5) Jürgen Habemas, Théorie de

l'agir communicationnel, tradução

francesa, Fayard, Paris, 2tomos,

1987, pp. 450-480.

6) Ver Réseaux, $n^{\circ} 34$, Autour

d'Habermas, março 1989.

Bernard Miège é Professor e Pesquisador junto à Universidade Stendhal, de Grenoble, na França.

Bernard Miège ${ }^{1}$

\title{
O espaço público: perpetuado, ampliado e fragmentado ${ }^{2}$
}

Nas sociedades mais desenvolvidas, a questão do espaço público é, certamente, objeto de posições paradoxais:

- por um lado, os próprios mediadores, que constituem uma categoria social "emergente", apelam cada vez mais ao espaço público, às suas regras supostas, à sua "operacionalidade"... e, mesmo se seus apelos são marcados de finalismo, seria um erro aqui ver somente um efeito de discurso;

- por outro lado, uma maioria de pensadores e de especialistas tem a tendência a desconfiar do conceito, ou mesmo de recusá-lo, ou somente de considerá-lo em segundo plano com as questões colocadas pela modernidade; entre eles, encontramos tanto autores que se interessam pela crise da representação política quanto teóricos da "in-comunicação", bem como Jean Baudrillard, Raymond Boudon, e mesmo Louis Quéré, que fala de "comunicação destrutiva"3 e privilegia a sociologia compreensiva e o interacionismo simbólico.

Porém, o mais importante é constatar que o próprio Jürgen Habermas se mostra reservado. Quase 30 anos depois do aparecimento da célebre tese sobre a arqueologia do "princípio de publicidade" e da sua dimensão constitutiva nas sociedades burguesas, o célebre autor alemão se mostra dividido. Ele sente por vezes a necessidade de redigir um novo Espace public $^{4}$, mas sob a forma de uma versão menos normativa que a primeira, livre das perspectivas (sedutoras) do EstadoProvidência; uma versão, enfim, que leve em conta mais as mediações sociais da comunicação do que aquelas referentes às mídias; uma versão que não negligencie a razão "sistêmica" no funcionamento das mídias (que ele, neste momento, tende a tomar como "determinante"), ao proveito da única razão "comunicativa". 5

A "aventura" teórica de Habermas é, a nosso ver, exemplar. Não somente porque sua produção científica é de grande qualidade (assim explicamos o porquê de escolas opostas terem tendência a se apropriar dela dando-lhes direções antagônicas), insuficientemente reconhecida na França e ainda não acabada; mas sobretudo porque ela se prende a analisar um dos problemaschave das sociedades contemporâneas: o espaço público é uma espécie de "linha vermelha" que coloca em jogo tanto o agir comunicacional quanto o futuro do político ou a constituição do liame social.

Nestas condições, há alguma desmedida em se colocar sobre um tal tema. Esperando que Jürgen Habermas e alguns outros ${ }^{6}$ avancem nesta via de reflexão, não hesitaremos em nos posicionar diferentemente, e em encarar deliberadamente as relações que se estabelecem entre as mídias ou as técnicas de comunicação e as mediações sociais para aí revelar certas "lógicas" constitutivas. Mais vale atualmente elaborar proposições "de médio alcance" do que se orientar pelas 
generalizações abusivas (isto é, não fundadas sobre um mínimo de validações empíricas), ou deixar os excessos de fluxo mediático responder às interrogações legítimas como estas: para onde nos conduz o marketing político generalizado? as mídias são, de início, o desmoronamento dos sistemas políticos da Europa Oriental? a fragmentação dos alvos das mídias comerciais leva à atomização social e à ruptura das solidariedades sociais elementares?

Como compreender o estatuto presente do espaço público, e as principais mudanças que o afetam, sem fazer um desvio pela história, ou mais exatamente sem buscar recompor as etapas pelas quais ele passou nas sociedades liberais-democráticas?

\section{Os quatro modelos de comunicação}

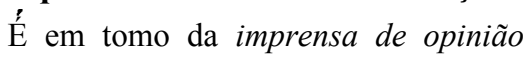
que se organizam os espaços públicos nascentes nas primeiras sociedades democráticas, em períodos diversos, conforme os países, antecedidos apenas pela Inglaterra em relação ao continente europeu e aos Estados Unidos.

Disseminada em toda a parte, em meados do século XVIII, esta forma de imprensa está disponível, apesar da oposição mais ou menos permanente da maior parte dos governos; ela é produzida mediante procedimentos artesanais, suas tiragens são reduzidas, seus ritmos de aparecimento (publicação) são irregulares e sua paginação é variável. Caracterizada por seu estilo polêmico, manifesta um tom de violência que hoje mal podemos imaginar. Os escritores que migram para o jornalismo garantem renome para os jornais para os quais colaboram.

Esta imprensa de idéias custa caro a seus leitores, que 'frequentemente são obrigados a contribuir nos custos da justiça e nas penalidades resultantes das opniões.

A partir deste contexto, no entanto, se estabelece uma proximidade muito grande entre os jornais e seus leitores, e é esta proximidade que permitiu aos burgueses esclarecidos praticar o Aufklärung, isto é, o uso público da razão para a argumentação e a troca de opiniões, e assim criar um espaço de mediação entre o Estado (habituado ao segredo durante a monarquia) e o espaço das vidas privadas. Neste sistema, as opiniões - ao menos aquelas dos burgueses envolvidos - não têm medo de se confrontar e de se afrontar (os cafés e os salões literários são os lugares privilegiados destas confrontações); assim, uma arbitragem se opera entre as opiniões e entre os interesses que elas exprimem. Elas são até mesmo capazes de se traduzir em representação política, sem recorrer à violência e à força. Tal é o modelo de comunicação original do espaço público que, embora limitado a uma classe (ascendente) das sociedades capitalistas em formação (uma classe definida ao mesmo tempo pela propriedade dos meios de produção e de troca, e por uma cultura específica), seduziu mais de um pensador social. Resta saber se ele foi algum dia aplicado como tal.

Em todo caso, a partir de meados do século XIX, e definitivamente no fim deste século, a imprensa comercial (cujo o destino está indissoluvelmente ligado ao regime parlamentar e ao “domínio" do território pelos notáveis) ${ }^{7}$ introduz mudanças decisivas, e um novo modelo de comunicação se implanta, sem que o anterior desapareça. As histórias da imprensa são ricas em detalhes sobre os fatores técnicos, jurídicos e econômicos que teriam assegurado em algumas décadas a supremacia da imprensa comercial; elas são em geral bastante discretas sobre as condições culturais e políticas de sua implantação, e elas não insistem de modo algum sobre os traços do novo modelo de comunicação. Ora, aí reside

o essencial. Com efeito, esta imprensa de "massa", organizada sobre uma base
7) Vero "triângulo imprensal parlamento/notáveis" posto em evidência por Yves de la Haye, Journalisme, mode d'emploi: des manières d'ecrire l'actualité, ELUG / La Pensée Sauvage, Grenoble, 1985, 216 páginas. 
industrial e orientada para o lucro, vê rapidamente as redações perderem sua autonomia em relação aos editores, e o jornalismo se separar da literatura. A linha política se afirma de maneira claramente menos polêmica, ela se dissimula mais ou menos sob o formato e a difusão das informações; a publicidade é a partir de então claramente dissociada da redação, e os gêneros jornalísticos (praticamente tal como nós os conhecemos hoje) se formam. $O$ poder político afirma a garantia da "liberdade de imprensa", e vai até mesmo, em certas circunstâncias, tomar medidas econômicas ou estatutárias de moralização de seu funcionamento. $\mathrm{O}$ importante, aqui, é notar que uma relação mercantil e distanciada se instaura entre os jornais e seus leitores (o caso dos jornais de opinião constitue uma exceção, mais ou menos durável segundo os países). "A opinião pública”, da qual a imprensa comercial se faz regularmente o eixo, se não responde às regras da manipulação e da propaganda, como muitos analistas e responsáveis políticos o afirmaram, apoiando-se em falhas bem reais, é antes de tudo uma "construção" e uma "representação" que se interpõe entre os leitorescidadãos mantidos afastados e os aparelhos político-informacionais, que assim melhor exprimem, as grandes categorias de opiniões.

Os efeitos das mídias audiovisuais de massa, que se impõem a partir de meados do século XX, são muito mais conhecidos. Eles se fizeram, de qualquer modo, o objeto de numerosos trabalhos de sociologia e antropologia culturais, e é neste propósito que Jürgen Habermas tanto insistiu sobre a ação sistêmica de "administração da cultura", incompatível com a publicidade e a confrontação das opiniões sobre a esfera pública.

De nossa parte, acrescentaremos que o desenvolvimento das mídias audiovisuais de massa (particularmente a TV aberta), está ligado quase organicamente ao da publicidade comercial (os "investimentos" dos anunciantes constituindo a base econômica do modelo, de forma integral ou em grande parte), e à ascensão das técnicas do marketing na comunicação social (alvo, estratégias de influência sobre os grupos e audiências, papel crescente da imagem e de um posicionamento de controle da imagem que veicula de si próprio...). Enfim, as mídias de massa, de modo ainda mais claro que a imprensa comercial, influenciam o divertimento, utilizado a partir de então, para acompanhar a difusão de informações ou da produção artística (ver, por exemplo, os talk shows); há uma primazia das normas do espetáculo e da representação em detrimento da argumentação e da "expressão".

O modelo mediático de massa é certamente $o$ modelo dominante na maior parte das sociedades liberaisdemocráticas. No entanto, desde o final dos anos 70, emerge com as relações públicas generalizadas (ou comunicação generalizada) um modelo novo, com o qual as mídias generalistas de massa devem ser cuidadosamente distinguidas. No futuro, os Estados, as grandes e pequenas empresas, e aos poucos, todas as instituições sociais (desde as poderosas administrações públicas às organizações da "sociedade civil") deverão apoderar-se das técnicas de gestão do social e das tecnologias da informação e da comunicação, e partem para estratégias de comunicação cada vez mais aperfeiçoadas. ${ }^{8}$ A imagem plena de sedução e de fluidez às quais estas técnicas e estratégias são objeto não se deve considerar como meros artefatos, ou como discursos vãos; elas são também poderosos "ativadores" de mudanças sociais e culturais. Sua aparição relativamente recente, no entanto, ainda não nos propiciou a dimensão dos resultados de seu poder. Parece patente que, ainda 
mais do que as mídias audiovisuais de massa, as próprias relações públicas generalizadas enfatizam os temas de consenso. Trata-se em todos os domínios da vida social, de conseguir adesão, e de se dirigir sobretudo aos indivíduos/consumidores/cidadãos, de preferência a grupos e "audiências". Inserindo-se nas relações sociais existentes e insinuando-se nas estruturas políticas e culturais em andamento, elas não têm o impacto "tautístico" que Lucien Sfez (entre outros) lhes empresta; mas é incontestável que elas são para as grandes organizações, as multinacionais, os partidos políticos dominantes e os Estados - que podem lhe consagrar os orçamentos de publicidade, de "comunicação", de patrocínio, de mecenato ... crescentes - elementos de reafirmação de sua dominação.

Tais são os quatro modelos de comunicação que, sucessivamente, se formaram e "organizam" o espaço público das sociedades liberaisdemocráticas. No entanto, importa acrescentar que:

- em uma dada sociedade, não há necessidade (estrutural) alguma para que tivessem dado lugar à quatro etapas sucessivas: assim, a imprensa de opinião pôde conhecer uma evolução muito rápida, encontrando-se rapidamente suplantada pela imprensa de massa; as relações públicas generalizadas podem assim ser somente uma etapa de partida...

- a emergência de um modelo novo não conduz ao desaparecimento dos modelos surgidos anteriormente; assistimos de algum modo a uma justaposição dos modelos, mais do que uma tutela dos "dominados" pelo "dominante": assim a televisão de massa não provocou o desaparecimento da imprensa comercial, a imprensa de opinião se mantém (entendida aqui como formas imprevistas, como atualmente as cartas confidenciais com intenção daqueles que decidem), as novas mídias acompanharão a radiodifusão generalista, etc...

- nos períodos-chave se operam as "oscilações", isto é, as passagens da dominação de um modelo a outro (por exemplo nos anos 60 quando a televisão foi reforçada em detrimento da imprensa); as mudanças que se seguem são verdadeiramente menos radicais do que as polêmicas do momento em que elas se dão;

- os modelos de comunicação assim definidos interagem estreitamente com a esfera política, ainda que de maneira muito variável; mas seria um erro pensar que as práticas comunicacionais e as práticas políticas se equivalem; é por este viés que Bernard Floris, seguindo as reflexões de Gilles Achache ${ }^{9}$, designa como as "formas transversais de comunicação" (a forma dialógica, a forma propagandista e a forma de marketing $)^{10}$, que se articulam no espaço público as lógicas sociais das mídias e o funcionamento do campo político;

- enfim, e este traço é raramente sublinhado, uma vez que ele é de uma importância capital, a colocação de cada novo modelo significa uma ampliação significativa dos públicos (e mesmo dos participantes) envolvidos, mesmo se esta se acompanha praticamente de um afastamento da participação no cenário público.

\section{Um espaço público assediado/ invadido por todas as partes}

$\mathrm{O}$ recurso aos quatro modelos de comunicação descritos acima ajuda a recolocar o espaço público em sua história de fundação. Se tais modelos permitem compreender algumas características do processo, difíceis de apreender fora do contexto desta estratégia, trata-se ainda de uma tentativa insuficiente por si mesma. Outros elementos devem ser colocados em evidência.

O espaço público frente às técnicas da
9) Ver a revista Hermès $n^{\circ} 4$, Le Nouvel Espace public, 1989. 10) Bemard Floris, Les Médiations sociales dans l'évolution de l'espace public, tese de doutorado de ciências da comunicação, Universidade Stendhal, Grenoble, reprodução gráfica, 1991, 400 páginas. 
comunicação (ou do marketing) política

Nas representações mais clássicas do espaço público, o modelo de origem está amplamente presente, isso se não for dominante. Esta faculdade de discussão crítica e de arbitragem entre as opiniões divergentes que os burgueses esclarecidos do século XVIII se impunham, ao mesmo tempo que eles a opunham à arbitragem do Estado monárquico, conserva um poder real de sedução, ao ponto que muitos autores contemporâneos (alguns, entre eles, essencialmente preocupados em afirmar a legitimidade e a superioridade do regime liberal das sociedades democráticas), limitam o espaço público à sua função política, até mesmo aos papéis que ele assume na cena política. Este reducionismo deve, por razões sobre as quais insistiremos na conclusão, ser criticado: a complexidade do funcionamento das sociedades modernas, de fato, conduziu o próprio espaço público a se tornar complexo e a ampliar suas competências. Mais uma outra crítica deve ser dirigida a estes mesmos autores, particularmente à alguns contribuidores do número da revista Hermès consagrada ao "novo espaço público" (Alain Touraine, Dominique Wolton, Raymond Boudon e mesmo Jean-Marc Ferry), que não estão longe de considerar que as técnicas modernas da comunicação política, não somente conduzem a uma modernização da vida política, mas sobretudo teriam uma função organizadora, lutando contra a entropia, a desintegração, a paralisia e a irritação políticas. $O$ espaço público político, a partir de então regulado e ativado pelas técnicas da comunicação política, seria assim uma resposta à crise da representação política e à apatia crescente dos cidadãos. Pierre Moeglin se levanta, com razão, contra esta concepção bastante conhecida do espaço público, sobretudo entre os "grandes" jornalistas, entre cientistas políticos e em uma parte da classe política que aceita ver-se confinada nas tarefas de mediação: "O aspecto mais contestável, escreve ele, é evidentemente o das sondagens efetuadas por reflexos da opinião pública [...] Mas isso vale também para os homens políticos cuja dimensão representativa pode ser enteirada com excessiva rapidez [...] E de modo parecido, para os jornalistas, cuja evocação não teimamos seja bastante idealizada". ${ }^{11}$ E Patrick Champagne concorda com ele com sua penetrante análise da função das sondagens: "Este modo de dominação é sem dúvida menos brutal do que quando a dominação é monopolizada por uma fração, mas ele é ainda mais poderoso, porque situado em parte alguma e por toda a parte, impessoal e múltiplo, aceito e submisso. Manifestado e sem dominantes claramente identificados...".12 Uma primeira conclusão se impõe: a pressuposta "superioridade" do espaço público (sobre outros sistemas de organização de "interação social") não deve ser buscada nas relações que este estabeleceu com as técnicas modernas de comunicação política; e mesmo estas, estão longe de ter mostrado efetivamente suas vantagens democráticas.

A penetração do espaço público na esfera privada

A maior parte dos analistas, sociólogos ou ensaístas, insistem na individualização das práticas culturais e comunicacionais; os dados disponíveis lhes dão razão, embora os movimentos observados sejam mais lentos do que o que eles geralmente anunciam (é o caso, por exemplo, da fragmentação do consumo televisivo). E Patrice Flichy confirma esta trajetória evolutiva com um visão a longo prazo: a tendência a "viver junto separadamente" ou no interior de "bolhas comunicacionais" particulares, assim como a diminuição da 
freqüência aos espetáculos coletivos constituem fenômenos marcantes e dificilmente contestáveis. ${ }^{13}$ Ao mesmo tempo, no entanto, cada indivíduo é levado a se pensar cada vez mais como indivíduo social e, de forma ativa, a fazer suas as normas de pertencimento social. Paul Beaud observa justamente que "graças sobretudo às ciências humanas, o espaço público penetra na antiga esfera privada e substitue seus instrumentos de comunicação pelas estruturas tradicionais de socialização". ${ }^{14}$ De fato, a difusão, vulgarizada ou não, das produções históricas, psicológicas e mesmo sociológicas, contribui para reforçar esta prática social com força crescente nas sociedades modernas: "a objetivação de si” (caracterização preferível à "intelectualização da vida privada", proposta por Raymond Boudon). A vulgarização das ciências e das técnicas contribui também para isso. Está claro que o fenômeno se encontra inegavelmente distribuído por classes e categorias sociais; ou melhor ainda, por pertencimento social, as estratégias de construção de sua relação objetivada pela sociedade sensivelmente diferente. E Paul Beaud, em oposição às teses de Habermas sobre a administração da cultura, insiste de modo pertinente na "ligação entre as práticas sociais e a evolução conjunta do espaço público e dos processos de comunicação", entre os quais as mídias e as técnicas de comunicação exercem "um papel socialmente diferenciado". Ainda conforme este autor, explica-se, deste modo, a razão pela qual, na França, o jornal televisivo das 20 horas conserva uma audiência muito grande e paira sobre as disputas televisivas: cada noite propicia uma ocasião importante para a população estabelecer contato com um conjunto mínimo de informações fundamentais (ainda que reduzidas à uma representação simplificada), e, deste modo, participar virtualmente de perto dos fatos do mundo. O jornal fornece também a substância regular para as interações sociais cotidianas, a matéria das conversas que se estabelecem no trabalho, nos transportes ou no lazer. Explica-se da mesma forma por qual razão esta invazão da esfera privada pelo espaço público (que funciona nos dois sentidos), se acentua na atualidade com o modelo das "relações públicas generalizadas”. Como observa Bernard Floris, "o relativo distanciamento da autoridade familiar, a exigência de autonomia e de iniciativa no trabalho, a exigência crescente de escolarização e de aculturação, constituem fatores de crescimento da demanda reflexiva no que se refere aos sistemas de representação e finalmente de interiorização autônoma das experiências e de conhecimentos sociais." 15

\section{A dimensão mercantil do espaço público}

Trata-se certamente do aspecto da evolução do espaço público mais desconhecido, e que pode, com o tempo, revelar-se o mais fundamental. $\mathrm{Na}$ verdade, aqui e acolá, os analistas modernos do espaço público fazem referência ao papel das normas mercadológicas, geralmente confundidas com os princípios do marketing (que não passam de uma declinação destes, entre outras). Permanece muito fértil, no entanto, a metáfora da contaminação, é como se um espaço público político "puro e perfeito" fosse (ainda) consebível; ou como se a extensão das normas mercadológicas apenas desencadeasse em sua esteira uma forma ideológica específica, até um modelo de organização entre outros. Ora, a dominação da mercadoria pertence primeiramente a um "modo de produção". Seja porque seus efeitos se observam prioritariamente na esfera do consumo, seja porque são particularmente visíveis na cultura, a regulação mercantil tenderá sempre a controlar o
13)Patrice Flichy, Une histoire de la communication moderne: espace public et vie privée, $L a$

Découverte, Paris, 1991, 285 páginas.

14) Paul Beaud, Médias, médiations et médiateurs dans la société industrielle, tese de doutorado do Estado de ciências de informação e da comunicação, Universidade Stendhal, Grenoble, 1986, 160 páginas.

15) Les Médiations sociales

dans l'évolution de l'espace public, op. cit. 
conjunto das práticas sociais.

Não devemos, também, nos espantar em encontrar agora o espaço público lá onde não esperamos encontrá-lo, mais precisamente na esfera da produção e nos lugares do trabalho. Certas funções das técnicas de comunicação de empresa são bem conhecidas: no interior das próprias empresas, elas contribuem para mobilizar as energias "participativas" ao serviço da reorganização do trabalho; em comparação ao ambiente social e cultural, elas melhoram sensivelmente a imagem que as empresas dão de si, indo até mesmo acentuar o lado “cidadão". É preciso verdadeiramente ir mais longe, e questionar como Bernard Floris se as empresas não estão em vias de alimentar novas relações com o espaço público, de um lado pela penetração dos valores e das posições empreendedoras no espaço público "geral", mas igualmente pela tendência em constituir o lugar do trabalho como espaço público "parcial", onde as informações fornecidas pelos serviços de comunicação tomam progressivamente o lugar daquelas anteriormente difundidas pelas organizações sindicais, ou em todo caso se justapõem a elas.

Ao término deste percurso, chegamos a uma proposição central: o espaço público contemporâneo, em nossa opinião, não poderia ser compreendido sem referência à sua história fundadora (e por conseqüência sem levar em conta a presença ativa dos quatro modelos de comunicação nas práticas comunicacionais), e sem uma percepção das três "lógicas sociais" principais que lhes orientam as mudanças. Deve-se evidentemente reconhecer o quanto, além das especificidades de cada sociedade, o espaço público é complexo.

Isso posto, e para avançar no conhecimento do espaço público, fazse necessário proceder às pesquisas ou validações empíricas quanto renovar as formulações teóricas. Os traços de um novo espaço público, no entanto, desde já vão surgindo.

Numa primeira análise, pode-se concluir que o espaço público se perpetua (ainda que se sua função de facilitador do debate e das trocas de opiniões, bem como o uso das práticas argumentativas tenham diminuido); que ele se amplia (todas as classes e categorias sociais são partícipes, porém, de modos diversos); que suas funções se estendem regularmente (as lógicas sociais que o "trabalham" estão na origem desta extensão); e que ele tem tendência a se fragmentar.

É este último traço que mais instiga questionamentos, pois a tendência à fragmentação repousa sobre:

- uma assimetria crescente: os indivíduos/sujeitos/cidadãos estão muito ocupados cada vez mais ligados aos dispositivos comunicacionais gerados pela maioria das instituições sociais, e se encontram assim em situação de "interação parcial" e provocada;

- uma desigualdade de participação que se acentua: para a leitura das cartas confidenciais e a participação de grupos de reflexão fechados, um quadro que dirige os meios de se comportar como um burguês esclarecido do século XVIII; este não é o caso de outras categorias sociais que se contentam com uma audiência mais ou menos regular do jornal televisivo;

- uma desigualdade de acessos aos meios modernos de comunicação que aumenta: o desenvolvimento das novas tecnologias reforça as diferenças entre uma minoria de dirigentes e de mediadores "super-equipados", e uma maioria de excluídos que se contentam com meios generalistas de massa;

- uma gestão cada vez mais sofisticada do consenso social e cultural: as diferenças, os conflitos e as oposições se exprimem menos com as relações públicas generalizadas do que com a imprensa de massa, que 
deixa se manter uma imprensa de

opinião e os meios de expressão das classes dominadas.

O espaço público, fundado hoje sobre uma multiplicidade de dispositivos e aparentemente constituído por uma justaposição de espaços "parciais" que não se comunicam entre si, não será jamais unificado? Há com o que se inquietar...

\section{Bibliografia do autor}

MIÈGE, Bemard (org.)- Capitalisme et industries culturelle - P.U.G - Grenoble, França, 1978.

MIÈGE, Bemard - La production du cinéma. - P.U.G - Grenoble, França, 1981.

MIÈGE, Bemard (org.) - Information, économie et société. Congrès INFORCON, P.U.G., Grenoble, França, 1982.

MIÈGE, Bemard - Playdoer pour les problematiques transversales et partielles. In: Miège, Bemard - Medias et Communication en Europe - P.U.G Grenoble, França, 1990.

MIĖGE, Bemard - La sociedad conquistada por la comunicacion ESRP/PPU/ Barcelona, Espanha, 1992.

MIÈGE, Bemard - La (necessaire) Voie étroite de la recherche en comunication, Rev. Intercom, n 1 /Vol XV, São Paulo, 1992.

MIÈGE, Bemard - L'espace public: perpétue, elargi, et fragmenté. In: Pailliart, Isabelle - L'espace public et 1'emprise de la communication, ELLUG, Grenoble, França, 1995.

MIĖGE, Bernard - El piensamento comunicacional. Universidad IberoAmericana, México, 1996. (A ser publicado em português, pela Ed. Vozes, no ano 2000) 